\section{UK review finds statins are cost effective in secondary prevention}

Zosia Kmietowicz London

Statins are most cost effective when used in patients with evidence of cardiovascular disease, in whom they reduce mortality as well as morbidity, according to a review by an advisory body to the NHS, the Health Technology Assessment.

The review is the 53rd in a series produced by the Health Technology Assessment designed to provide the NHS with information on the most efficient way of using new technologies. Data from five major trials of statins and 18 randomised controlled trials showed that statins reduced overall mortality in people with cardiovascular disease by $21 \%$ and deaths from coronary heart disease by $26 \%$. The report con-

sidered that statins were less effective when used for primary prevention. In people with no evidence of cardiovascular disease, statin treatment reduced morbidity (such as non-fatal myocardial infarctions) but not overall or cardiovascular deaths.

In the trials considered in the review the cost effectiveness of statins ranged from $£ 5400$ $(\$ 8640)$ to $£ 13300$ per life year gained in primary prevention and from $£ 3800$ to $£ 9300$ for secondary prevention, varying according to the cost of the statin and the risk of coronary heart disease in the population treated. This was much higher than the cost effectiveness of aspirin, which was calculated as

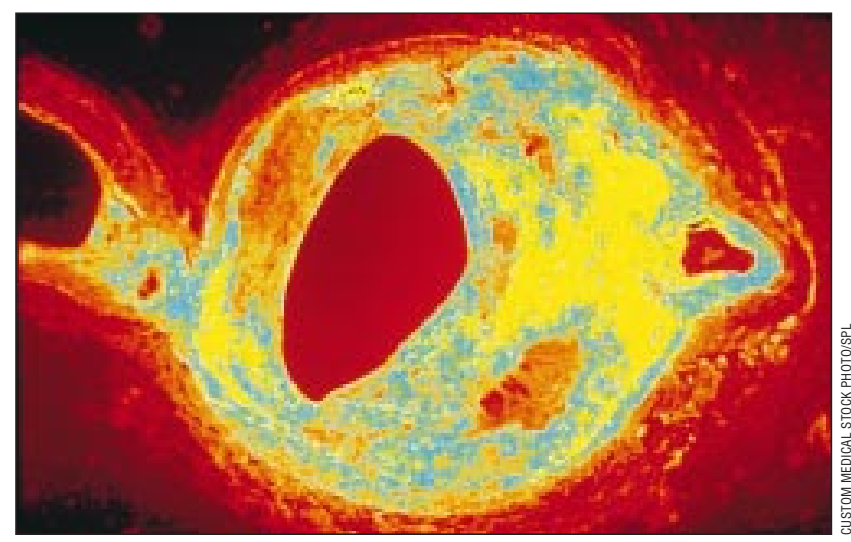

Cross section of an atheromatous plaque in a human artery being $£ 53$ per life year saved, and of other treatments for cardiovascular disease, such as antihypertensive regimens (£1509), $\beta$ blockers after myocardial infarction (£227), and a Mediterranean diet after a myocardial infarction (£293). But even at their higher cost, the use of statins was considered to be acceptable in secondary prevention because of the benefits.

Dr Nick Payne, senior lecturer in public health medicine at the School of Health and Related Research at the University of Sheffield and an author of the report, commented that the review indicated that hypercholesterolaemia in isolation should not be treated with statins. "The level of risk is an important assessment when making a decision to treat, especially for primary prevention of coronary heart disease. Age, sex, blood pressure, smoking, and diabetes status all need to be taken into account, as well as cholesterol level," he said.

Lowering the price of statins would greatly improve their cost effectiveness and would allow more patients to be treated, according to the review. It said that "there may be a case for further examining the prices of statins, given the very large potential market of these drugs in primary prevention."

What Role for Statins? A Review and Economic Model can be ordered (free to staff working in the UK public sector) via fax (01703 595639) or email (hta@soton.ac.uk).

\section{Japan moves towards legal ban on human cloning}

Joe Lamar Toyko

Japan moved closer to imposing a legal ban on human cloning when an advisory body to its prime minister, Keizo Obuchi, ruled last week that current guidelines were inadequate.

The panel, a subcommittee of the Science and Technology Council, argued that cloning has no positive utility, runs counter to respect for human life, and poses safety problems. It recommended the establish- ment of penalties to deter scientists from such research. "We believe we have clearly drawn a line against any attempt [towards cloning] at a time when the general public is growing wary of technological progress," said Yoshio Okada, the head of the panel.

According to the Yomiuri Shimbun newspaper, the government is already preparing to submit a bill to parliament in January based on the panel's recommendations. If passed, the bill would be the first legal prohibition of life science research in Japan and would significantly tighten existing regulations on cloning. Currently, the government has banned such research through administrative guidelines, which apply only to state run institutions and carry no penalties for violators.

The problems with this approach have become apparent in the past year. In December 1998, US scientist Richard Seed announced plans to set up a private human cloning clinic in Japan. Earlier this month, it also emerged that a research group at Tokyo University of Agriculture had used cloning technology to look for a cure for leukaemia.

The advisory panel did not completely slam the door on human cloning. It reached no conclusion on whether embryonic stem cells should be used to create fetuses for research purposes. It also suggested that any new law should be reviewed within five years.

\section{BMA welcomes plans to regulate private care}

Linda Beecham $B M J$

The government will introduce the Care Standards Bill in the forthcoming session; the bill is designed to regulate private and voluntary healthcare and social care services.

The bill to regulate private hospitals and clinics in England and Wales, which was announced in the Queen's speech last week, will also introduce independent inspection of all care homes, including those owned by local councils, by eight regional care commissions.

The government's decision to strengthen the regulation of the private healthcare sector follows the publication in July of a report from the parliamentary select committee on health which said that current regulations were "inadequate for the task of protecting the public" (31 July, p 276).

The BMA says that the proposals support its view of the need to establish a regulatory framework for the independent healthcare sector. It wants regulation to recognise good practice and focus on the policing of "errant areas." The association also believes that, because there are many different settings in which care is provided, regulation should be process oriented rather than premises oriented. Private facilities in the NHS should be regulated in the same way as the independent sector.

The BMA hopes to be fully involved in developing national standards for the new arrangements.

The bill will also set up a General Social Services Council to oversee the standards, training, and staff discipline of those working in social care. The BMA welcomes the decision to set up a council: it had asked the government to look at the possibility of setting up a national regulatory body for the social work profession in 1991.

The BMA says that there should be medical representatives on the council to ensure that the health aspects of care are given due weight. 